\title{
Spondyloarthritis: Harlequin or Chameleon?
}
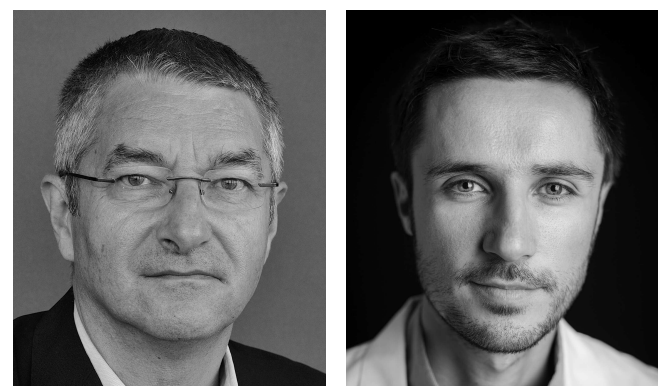

Spondyloarthritis $(\mathrm{SpA})$ is a chronic inflammatory disease ${ }^{1}$ encompassing several previously nosologically defined rheumatologic entities (ankylosing spondylitis, reactive arthritis, psoriatic arthritis, inflammatory bowel disease-associated arthritis, undifferentiated spondyloarthritis), with a new terminology ${ }^{2,3}$. These conditions share common features in the rheumatologic domain (predominant and frequent axial involvement, enthesitic involvement, possibility of dactylitis) and in the immunogenetic domain (HLA-B27, endoplasmic reticulum aminopeptidase-1, or interleukin 23R polymorphisms). They also share extraarticular manifestations: psoriasis, uveitis, and inflammatory bowel diseases (IBD). These extraarticular manifestations are important to consider. They may help to diagnose SpA, and in a case of inflammatory back pain, presence or history of anterior uveitis (AU), psoriasis, or IBD is crucial for the clinical certainty of the diagnosis. Logically, they are part of the several classification criteria for $\mathrm{SpA}^{4}$. They are also to be considered at a therapeutic decision level; for example, coexistence of active IBD should prompt the clinician, in case of indication of a tumor necrosis factor (TNF) blocker for $\mathrm{SpA}$, to favor a monoclonal antibody rather than a soluble receptor ${ }^{5}$. These extraarticular features also represent the most frequent expression of the so-called "paradoxical" effects of TNF antagonists in the treatment of SpA. Moreover, IBD is of particular importance in the current pathophysiological hypotheses of $\mathrm{SpA}^{6}$. Under these circumstances, one question arises regarding extraarticular manifestations in SpA: Are they associated with a particular presentation of the disease?

In this issue of The Journal, Cantini, et al ${ }^{7}$ evaluated the frequency of dactylitis, enthesitis, and $\mathrm{AU}$ in SpA associated with IBD (IBD-SpA) compared to non IBD-SpA (both fulfilling Assessment of Spondyloarthritis international Society criteria), and to evaluate the effect of psoriasis on dactylitis and enthesitis presence in patients with IBD-SpA. In this case-control, cross-sectional study, dactylitis, enthesitis, and AU were significantly less frequent in IBD-SpA, compared to the other SpA. In IBD-SpA, presence of psoriasis was associated with the same frequency of dactylitis and enthesitis versus overall $\mathrm{SpA}$. These results underline that some extraarticular manifestations may be associated with a different clinical presentation of rheumatologic symptoms. The lower frequency of HLA-B27 positivity in IBD-SpA may account for the low number of $\mathrm{AU}$ in this group of patients. Of interest, and in contrast to enthesitis and dactylitis, the number of AU remained low in IBD-SpA patients with psoriasis, confirming that uveitis in SpA is more HLA-B27-related than psoriasis- or IBD-related. This may illustrate different pathogenic pathways in the several extraarticular features in $\mathrm{SpA}$. The mean disease duration was somewhat longer in IBD-SpA versus overall SpA (60 vs 43 months) ${ }^{7}$, and this may not explain the observed difference in enthesitis, dactylitis, and AU frequencies. Moreover, in nonradiographic axial SpA (39 out of 176 overall SpA patients) ${ }^{7}$ with shorter disease duration (mean 23 mos), enthesitis, dactylitis, and $\mathrm{AU}$ frequencies were higher than in patients with IBD-SpA.

In early stages of SpA, such as in the French DESIR cohort of patients with recent inflammatory back pain suggestive of $\mathrm{SpA}^{8}$, presence or history of psoriasis (in 16\% of the cases) or uveitis (8\%) were found to be associated with particular characteristics. In the case of psoriasis, enthesitis was more frequent, Bath Ankylosing Spondylitis Disease Activity Index (BASDAI), and Functional Index (BASFI) more elevated, and C-reactive protein (CRP) higher compared to nonpsoriatic patients ${ }^{9}$. No difference was seen in radiographic or magnetic resonance imaging (MRI) axial findings, but erosion and vascularization of Achilles enthesis were more frequent. In multivariate regression analysis, dactylitis was an independent predictor of psoriasis. In this cohort, the presence of uveitis was significantly associated, in univariate analysis, with a previous diagnosis of IBD, Achilles enthesitis, and in multivariable analysis, presence of $\mathrm{IBD}^{10}$. These results may argue for an association of

\section{See IBD-SpA coexistent psoriasis, page 1341}


modification of the clinical picture of $\mathrm{SpA}$ with some extraskeletal manifestations.

Could the grouping of rheumatic and extrarheumatic symptoms define some phenotypic presentations? Costantino, et $a l^{11}$ were able, using a cluster analysis, to classify the patients of the DESIR cohort into 2 phenotypes, one with predominant axial manifestations, and one with predominant peripheral manifestations. In the latter, dactylitis, arthritis, and psoriasis were more frequent, with higher disease activity and less response to nonsteroidal antiinflammatory drugs. Power Doppler-positive ultrasound enthesitis was also more frequent, whereas there was no difference in HLA-B27, AU, IBD frequency, CRP level, or sacroiliac imaging. Whether these phenotypic presentations have different outcomes (i.e., disease severity) is a question under evaluation.

In their study, Cantini, et $a l^{7}$ found differences between IBD-SpA versus SpA. IBD was confirmed by a gastroenterologist. We do not know whether patients with non-IBD SpA underwent ileocolonoscopy; this may be of importance because microscopic asymptomatic bowel inflammation is frequent in $\mathrm{SpA}^{6}$. Gut inflammation is linked to the degree of bone marrow edema found with MRI of the sacroiliac joints in axial $\mathrm{SpA}^{12}$, and is associated with young age, male sex, elevated disease activity (assessed by BASDAI), and impaired function (assessed by BASFI), but not with presence or history of enthesitis ${ }^{13}$. Independently of SpA, Orchard and colleagues ${ }^{14,15}$ proposed a classification of inflammatory peripheral joint involvement in IBD in 2 types (each associated with a particular immunogenetic background and some extraarticular features). Type I arthritis is a pauciarticular, time-limited arthritis, associated with extraintestinal manifestations and IBD flares. Type II is persistent, polyarticular, less related to IBD activity, and associated with uveitis. These suggest a phenotypic aggregation of articular and extraarticular manifestations.

Is $\mathrm{SpA}$ only the juxtaposition of characteristics, like a harlequin costume, or could the presentation change according to the context or presence of extraarticular manifestations, like a chameleon, with some associations corresponding to different phenotypic presentations? In each of these situations, the clinical picture is of importance and a major help for the diagnosis of SpA.

\footnotetext{
DANIEL WENDLING, MD, PhD,

Professor of Rheumatology, Head, Department of Rheumatology, CHRU (University Teaching Hospital) Besançon; EA 4266, Université Bourgogne Franche-Comté, Besançon, France;

CLÉMENT PRATI, $\mathrm{MD}, \mathrm{PhD}$,

Associate Professor of Rheumatology, Department of Rheumatology, CHRU Besançon; EA 4267 PEPITE, and FHU Increase, Université Bourgogne Franche-Comté, Besançon, France.
}

Address correspondence to Prof. D. Wendling, Department of Rheumatology, CHRU Besançon, Boulevard Fleming, 25030 Besançon, France. E-mail: dwendling@chu-besancon.fr

\section{REFERENCES}

1. Taurog JD, Chhabra A, Colbert RA. Ankylosing spondylitis and axial spondyloarthritis. N Engl J Med 2016;374:2563-74.

2. Claudepierre P, Wendling D, Breban M, Goupille P, Dougados M. Ankylosing spondylitis, spondyloarthropathy, spondyloarthritis, or spondylarthritis: What's in a name? Joint Bone Spine 2012; 79:534-5.

3. Wendling D, Claudepierre P, Prati C, Dougados M. Spondyloarthritis: A concept or a disease? Joint Bone Spine 2015;82:387-9

4. Lekpa FK, Wendling D, Claudepierre P. Spondyloarthritis: criteria limitations, and perspectives throughout history. Joint Bone Spine 2015;82:390-3.

5. Wendling D, Lukas C, Paccou J, Claudepierre P, Carton L, Combe B, et al. Recommendations of the French Society for Rheumatology (SFR) on the everyday management of patients with spondyloarthritis. Joint Bone Spine 2014;81:6-14.

6. Wendling D. The gut in spondyloarthritis. Joint Bone Spine 2016;83:401-5

7. Cantini F, Nicoli L, Nannini C, Cassara E, Kaloudi O, Rizzelo F, et al. Case-control study on dactylitis, enthesitis, and anterior uveitis in spondyloarthritis associated with inflammatory bowel disease: role of coexistent psoriasis. J Rheumatol 2017;44:1341-6.

8. Dougados M, Etcheto A, Molto A, Alonso S, Bouvet S, Daurès JP, et al. Clinical presentation of patients suffering from recent onset chronic inflammatory back pain suggestive of spondyloarthritis: The DESIR cohort. Joint Bone Spine 2015;82:345-51.

9. Richette P, Tubach F, Breban M, Viguier M, Bachelez H, Bardin T, et al. Psoriasis and phenotype of patients with early inflammatory back pain. Ann Rheum Dis 2013;72:566-71.

10. Wendling D, Prati C, Demattei C, Miceli-Richard C, Daures JP, Dougados M. Impact of uveitis on the phenotype of patients with recent inflammatory back pain: data from a prospective multicenter French cohort. Arthritis Care Res 2012;64:1089-93.

11. Costantino F, Aegerter P, Dougados M, Breban M, D’Agostino MA Two phenotypes are identified by cluster analysis in early inflammatory back pain suggestive of spondyloarthritis: results from the DESIR cohort. Arthritis Rheumatol 2016;68:1660-8.

12. Van Praet L, Jans L, Carron P, Jacques P, Glorieus E, Colman R, et al. Degree of bone marrow oedema in sacroiliac joints of patients with axial spondyloarthritis is linked to gut inflammation and male sex: results from the GIANT cohort. Ann Rheum Dis 2014; 73:1186-9.

13. Van Praet L, Van den Bosch FE, Jacques P, Carron P, Jans L, Colman R, et al. Microscopic gut inflammation in axial spondyloarthritis: a multiparametric predictive model. Ann Rheum Dis 2013;72:414-7.

14. Orchard TR, Thiyagaraja S, Welsh KI, Wordsworth BP, Hill Gaston JS, Jewell DP. Clinical phenotype is related to HLA genotype in the peripheral arthropathies of inflammatory bowel disease. Gastroenterology 2000;118:274-8.

15. Orchard TR, Wordsworth BP, Jewell DP. Peripheral arthropathies in inflammatory bowel disease: their articular distribution and natural history. Gut 1998;42:387-91.

J Rheumatol 2017;44:1293-4; doi:10.3899/jrheum.170452 